\title{
CIEN AÑOS DE SOLEDAD EN BERLÍN
}

\section{ONE HUNDRED YEARS OF SOLITUDE IN BERLIN}

David Dellenback*

¿Será que existen fuera de Colombia estatuas en piedra originarias de San Agustín y de otros sitios del Macizo Colombiano? La respuesta indudablemente es positiva. Ellas adornan los jardines y las colecciones privadas de la gente rica y poderosa del mundo. Después de todo, los huaqueros no han cesado de trabajar en el valle de San Agustín, y el fruto de ese huaqueo flota en el mercado negro. Los resultados finales son muchas operaciones ilegales, camufladas cuidadosamente, que hacen que ciertas cosas (en nuestro caso las esculturas) salgan del 'Valle de las Estatuas' y caigan en las manos de gente que le sobra el dinero.

Pero, ¿Qué de la estatuaria cuya existencia es de conocimiento público, la que se exhibe o se publica abiertamente, las esculturas que están registradas y son accesibles al público, en vez de estar en la clandestinidad? Sin lugar a duda, la colección más grande de ese tipo de artículos se encuentra en Berlín, Alemania, en el museo etnológico precolombino ubicado en el suburbio de Dahlem.

La historia es la siguiente: En 1911, hace un siglo, Machu Picchu en el Perú fue 'descubierto' por el profesor universitario norteamericano Hiram Bingham, quien llegó a la fama al hacerse Senador de los EE. UU. gracias a su conmemorada hazaña; mientras tanto, al otro lado del mundo, el alemán Konrad Theodor Preuss, siendo el director del Museo Etnológico de Berlín, se reunió con su compatriota, el cartógrafo Karl Stoepel. Los dos hablaron de las estatuas del pueblo de San Agustín en las lejanías de Colombia. Stoepel ya tenía previsto un viaje a Suramérica, y llegó a San Agustín antes de terminar ese año; allí estuvo un mes, hizo moldes de varias de las estatuas y luego regresó con ellos a Europa. Por ello, el viaje exploratorio que el profesor Preuss planeaba a la tierra de las estatuas había recobrado aún más ímpetus.

Cuando Preuss finalmente estaba listo para partir a San Agustín, el viaje no le fue fácil: le tomó 12 días navegando por el Río Magdalena para ir de Barranquilla a Girardot, además de otros 16 días de viaje a lomo de mula para cumplir su meta. Para diciembre de 1913, Preuss ya había llegado a San Agustín, de donde partió en los primeros días de abril de 1914. Su intención era hacer lo que más pudo durante su corto pero fructífero viaje, y luego regresar a ejercer su profesión en Alemania. Sin embargo, el destino le había deparado diferentes planes al visitante: la Primera Guerra Mundial cerró los medios de transporte a través del Océano Atlántico, de manera que tuvo que quedarse en Colombia no solo por algunos meses más, sino durante seis años. Solo hasta el final de la guerra, en 1919, Preuss pudo regresar a Europa y embalar su preciada carga de antigüedades hacia el Viejo Mundo, hacia su propio museo en Berlín.

Sin embargo, el mundo al que regresó no era el esplendoroso Berlín que había dejado en 1913, antes de la guerra. Alemania ya estaba derrotada y postrada, el mundo de la capa social de Preuss estaba fragmentado; el surgimiento de Hitler se acercaba. [Preuss moriría en 1938 en un Berlín ya convulsionado por la guerra inminente, cuando todavía los famosos '1000 años del Reich' estaban en sus fases iniciales.]

Preuss partió de Colombia en 1919; solo hasta el año 1923 pudo reensamblar en su museo el tesoro del Macizo, y con ello montar la exposición en Berlín, la cual entre las clases educadas de Europa despertó por primera vez gran interés en la estatuaria del Macizo Colombiano. El

\footnotetext{
Norteamericano, oriundo del Estado de Oregón. Radicado en el país hace tres décadas. Ha estudiado junto a su esposa, la historia del Macizo Colombiano y del Pueblo Escultor (conocido popularmente como la Cultura San Agustín). Recientemente publicó el libro Las estatuas del pueblo escultor. San Agustín y el Macizo Colombiano en versión bilingüe español-inglés.www.sanagustinstatues.org
} 
conocimiento de nuestras estatuas en 'Todo el Mundo' se inició por los esfuerzos de Preuss.

Preuss llevó consigo 21 esculturas originales del Pueblo Escultor del valle de San Agustín (así como muchos moldes tomados de las estatuas más grandes). También se llevó una gran cantidad de cerámica antigua y otros artefactos, los cuales, así como las esculturas, él mismo documentó detalladamente en su libro, Arte Monumental Prehistórico. Este libro, el cual ha sido la guía obligatoria de las estatuas de San Agustín, apareció en español en Colombia al principio de 1931, fue reeditado en 1974, y hoy en día es difícil de conseguir.

Preuss no llevó las estatuas más grandes únicamente porque no tenía la forma de transportarlas. Él se fue con lo que pudo, es decir con todo lo que era relativamente 'pequeño.' Sin embargo, muchas de las estatuas que se llevó miden cerca de un metro y hasta más, la mayoría son extremadamente pesadas y por supuesto, muchas de ellas son piezas hermosas.

Indudablemente el razonamiento de Preuss (tal vez un sofismo) era que si removía las estatuas de sus lugares originales, es decir de los alrededores de San Agustín, y las llevaba con él a su museo en Berlín, las estaba sacando de la soledad y del peligro de estos inhóspitos parajes selváticos, en donde «cualquier cosa puede pasarles», y las llevaba a un lugar más seguro, estable y con más conocimiento técnico, como Berlín, donde las podría cuidar y mantener adecuadamente. Por supuesto, la ironía es que en realidad las llevó directo y precisamente hacia el ojo de la tempestad, a Berlín, al blanco principal de la Segunda Guerra Mundial, lugar en donde unos pocos años después de la muerte de Preuss, las fuerzas aéreas de Inglaterra y USA desataron bombardeos de una ferocidad nunca vista antes en ninguna parte del planeta. La ciudad de Berlín quedó completamente arruinada, mientras que el valle y el pueblo de San Agustín continúan en paz y hasta ahora sin bombardeos.

Milagrosamente, la mayoría de estatuas que Preuss llevó a Alemania sobrevivieron la destrucción general. Sin embargo, la gran colección de cerámicas y otros artefactos no corrió con la misma suerte; todos estos objetos, como lo pudo constatar el autor de este ensayo, quedaron reducidos a unas cuantas cajillas llenas de pedacitos.

Demos un salto adelante, al año 1992 cuando el autor hizo una investigación en el lugar donde el botín de
Preuss-nuestras hijas pródigas las estatuas-se encuentran descansando, allí precisamente en el museo etnológico de Berlín. Las autoridades del museo le dieron una bienvenida de 'brazos abiertos,' y le contaron que durante los 70 años que han permanecido las estatuas en Berlín no existía registro de la visita de ningún investigador colombiano que haya llegado al Museo con el fin de estudiarlas, cosa que suena ridícula, pero que resulta ser cierta. Los alemanes actuaron como esponjas: le recibieron amablemente y en un mes, además de lo que ya sabían, también sabían todo lo que el autor había investigado de las estatuas. Sin problema le dieron la entrada a todas las inmensas bodegas subterráneas, las cuales accedió cada mañana a través de sus 13 bien aseguradas puertas.

El primer punto impactante fue el siguiente: Solamente tres de nuestras estatuas estaban en exhibición en ese enorme y espectacular museo. El autor llegó allí pensando que iba a ver las 21 piezas que Preuss documentó. ¿Dónde se encontraban las otras? El misterio se aumentó cuando los del museo le mostraron siete estatuas más de Preuss en las bodegas del sótano y le dijeron que eso era todo lo que tenían. Un total de diez. ¿Y las demás qué? De inmediato tuvo permiso para buscarlas; las bodegas eran inmensas, pero para consultar contaba con los textos e inventarios originales hechos por Preuss.

Eventualmente, después de una larga búsqueda, encontró las otras estatuas en un rincón de ese oscuro laberinto, tan abandonadas y desoladas como Preuss había descrito al pueblo de San Agustín; estaban amontonadas, dentro o debajo de unos escaparates de madera anticuados y relegados. Estaban extraviadas entre muchos trasteos de museo a museo, perdidas en vastos corredores repletos de tesoros; lo del Macizo se había esfumado en la confusión, arrinconado y finalmente olvidado. Aparentemente durante setenta años, ahora noventa, ese había sido el destino de estas estatuas.

Las autoridades del museo le agradecieron al autor por la nueva información sobre las estatuas, y también por ayudarles a tener la colección de Preuss nuevamente organizada. De las 21 esculturas que esperaba encontrar, pudo identificar, ilustrar y estudiar 17. Varias de ellas, aunque todavía completas, se habían roto después de las fotografías tomadas por Preuss. Es posible-ojalá-que allí están las otras cuatro por él publicadas, y que simplemente escaparon de la vista. 
Pero para gran sorpresa, además encontró en los polvorientos sótanos del museo otras 14 estatuas del Macizo Colombiano, escondidas y perdidas de su entorno. Todas ellas hasta ese momento eran desconocidas para los funcionarios del museo y nunca fueron publicadas 0 reconocidas por Preuss, pero el lector de este ensayo las puede ver, junto con el catálogo completo de la estatuaria del Macizo Colombiano, en el libro Pueblo Escultor y en el sitio virtual (www.sanagustinstatues.org" www. sanagustinstatues.org). Estas 14 piedras no son del valle de San Agustín; todas ellas son originarias de otros sitios del Pueblo Escultor ubicados en el departamento de Nariño (en las zonas de Iscandoy y Briceño), el cual Preuss recorrió al partir del Valle de las Estatuas y de las cabeceras del Río Magdalena. Ninguna de las estatuas de Nariño estaban en exhibición en el museo en Berlín.

Esto nos conduce a un punto importante: Preuss llevó 35 de nuestras estatuas a Alemania; solamente hay tres en exhibición. Nadie las observa todas; 32 de ellas se encuentran literalmente olvidadas en los pasillos de las bodegas, visitadas por nadie. Ningún colombiano las ve; claramente ellas son de poca importancia para los alemanes, y lo peor es que, para nosotros, a este lado del océano, tampoco han resultado ser de mucho valor.

Recientemente se publicó un artículo acerca del famoso busto egipcio de la Nefertiti, el cual también está en un museo arqueológico de Berlín. Aunque los egipcios veneran la estatua y anhelan profundamente su regreso, los alemanes también la admiran, la tienen en constante exhibición, y le dicen a los egipcios que la Nefertiti le pertenece a Alemania y que permanecerá en Berlín. Sin embargo, Egipto no se rinde: durante 85 años han requerido formal y apropiadamente, desde los niveles gubernamentales más altos, el regreso del tesoro que les pertenece, y hoy en día continúan haciendo la petición. Esto hace que el mundo vea y sienta el problema latente: los egipcios quieren a su Nefertiti de regreso a su hogar. Algún día lo lograrán.

Hay que recordar que en el año 2011 los EE. UU. y la Universidad de Yale, tal como lo habían acordado, empezaron a devolver los primeros lotes de los vastos tesoros despojados hace un siglo de Machu Picchu, y en el 2012 se llevó a cabo la devolución del último lote de esas reliquias al Perú, donde podrán estar en exposición pública.
Colombia, en un siglo, nunca había requerido formalmente la devolución de la estatuaria que Preuss se llevó a Alemania. Las autoridades arqueológicas no habían ido a estudiarlas, ni habían mostrado interés en empezar las conversaciones para su retorno. Los alemanes no tienen mucho interés particular en nuestras estatuas del Macizo, como sí lo tienen con la Nefertiti, pero hasta ahora tampoco han tenido razón para creer que a Colombia $\mathrm{O}$ a los colombianos les importan. Obviamente nada pasará hasta que Colombia al menos inicie, para después proseguir enérgicamente, el proceso formal de requerir su repatriación.

Mientras tanto, la situación referente a las estatuas en Berlín ha cambiado; ya no son figuras anónimas, ya mucha gente dentro y fuera de Colombia comparte una consciencia de su existencia. Empezando con las firmas de 1800 agustinenses al derecho de petición, dirigido al ICANH y al Ministerio de Cultura, que exige acción en la repatriación de las estatuas, el tema ha despertado gran interés periodístico y la noticia de la campaña para la repatriación se ha emitido ampliamente por los medios de comunicación: internet, radio, prensa y televisión. Tanto en el Huila como en Colombia y fuera del país, líderes civiles, políticos, académicos y de muchas otras posiciones se han unido en palabra y en acción en pro de la reclamación de las estatuas. Crecientes números de visitas llegan a la página web y se unen a la página del facebook: 'repatriación estatuas Colombia'.

Sin embargo, siguen vigentes las mismas preguntas: ¿Cuándo llegará el día del retorno a su casa de esos tesoros desconocidos, abandonados en un sótano en Berlín? ¿Quién tomará la iniciativa y hará algo para proteger nuestro patrimonio extraviado? ¿Qué más se puede hacer para comunicarles a los alemanes que aquí en Colombia sí hay gente a quien le importa la historia y el destino de estas ancestrales estatuas?

Postdata: Cuando llegue ese día en que los alemanes las devuelvan, ¿Qué hará Colombia con las estatuas? ¿Cómo las trataremos?, teniendo presente que su sitio original es el Macizo Colombiano, y no la sabana de Bogotá. Da lo mismo yacer en una bodega en Bogotá que en un triste sótano en Berlín. El equilibrio y el descanso solo les llegará, y al pueblo el sosiego, el día en que ellas vuelvan a su hogar milenario, al Macizo en donde hace muchos siglos fueron creadas. 